\title{
Coenzyme q10 is potentially usedto improve lipid profile in diabetic hypercholesterolemia- induced periodontitis in the coastal area
}

\author{
Saryono Saryono ${ }^{1, *}$, Hesti Devinta ${ }^{2}$, AbdulHarisBudi Widodo $^{2}$, and ArifImam Hidayat ${ }^{1}$ \\ ${ }^{1}$ School of Nursing, Faculty of Health Sciences, University of JenderalSoedirman, Indonesia \\ ${ }^{2}$ Dentistry Department, Faculty of Medicine, University of JenderalSoedirman, Indonesia
}

\begin{abstract}
Contaminated water often affects the occurrence of periodontitis in the coastal area. The diabetic hypercholesterolemia-induced periodontitis in Indonesia is very high. The use of coenzyme Q10 to treat this disease has never been investigated yet. Therefore, this study aimedto analyze the effect of coenzyme Q10 on the lipid profile of diabetic hypercholesterolemia-induced periodontitis.Twenty four rats were randomized into 6 groups (G1-G6). The groups (G1-G3) are healthy, negative and positive control group respectively. The treatment groups (G4-G6) are diabetic hypercholesterolemia-induced rats given coenzyme q10 dose of 13,$5 ; 27$ and $54 \mathrm{mg} / \mathrm{kg}$ respectively. Rats were induced by periodontitis, hypercholesterolemia and diabetes mellitus. Coenzyme Q10 was administered orally using $2 \mathrm{~mL}$ gastric tube once a day for 14 days. Lipid profile including triglycerides, HDL, and atherogenic index (IA) was measured enzymatically by the CHOD-PAP method. Data were analyzed by one-way ANOVA test and followed by the Least Significant Difference (LSD) post hoc test.Coenzyme Q10 with a dose of $54 \mathrm{mg} / \mathrm{kgis}$ effective in lowering triglyceride, and atherogenic index and increasing HDL level in diabetic hyperlipidemia-induced periodontitis rats model. This research supports the potential effects of coenzyme Q10 supplementation to improve lipid profile in diabetic hypercholesterolemia-induced periodontitis in the coastal area.
\end{abstract}

Keywords: coenzyme Q10, lipid profile, hypercholesterolemia, diabetes mellitus

\section{Introduction}

Water is the source of life. The water content in the body reaches more than $50 \%$ in adults. The more densely populated in a region, the water quality gets worse. Contaminated water will have an effect on tooth health[1,2]. Drinking water from surfaces area are generally salty in the coastal areas, so people prefer to dig the wells that contain lots of calcium and phosphate. High levels of calcium, phosphate and other minerals in drinking water in coastal areas play a role in increasing the high prevalence of periodontitis[3].

This water will make the teeth become more easily perforated and damage the periodontal tissue causing periodontitis as well. Periodontal disease in Indonesia is the second number after caries [4]. The prevalence of periodontal disease in Indonesia was $96.58 \%$. While the prevalence of periodontal disease in coastal communities amounted to $10.43 \%$ of 2157 elementary school students in Jepara in 2011[5]. Calcium and phosphate

*Corresponding author: sarbiokim@gmail.com 
mineral intake as a material of tartar (the main cause of periodontal disease) is very high, especially in coastal communities. Periodontitis disease will be more severe when the patient has diabetes. Prevalence of periodontitis in DM patients at Internal Medicine Polyclinic, Dr. Sardjito General Hospital is $88.24 \%$ [6].

Diabetes mellitus is a metabolic disorder with the highest prevalence in Indonesia.It often leads to complications of hypercholesterolemia. Excess cholesterol in the body will increase in the atherogenic index[7]. Lipids are the most potent compounds to be oxidized. Lipid peroxidation products form intermolecular bonds with the amino-terminal group of low-density lipoprotein (LDL) apolipoprotein to form oxidized LDL. This will increase the risk of atherosclerosis formation which is coronary heart disease (CHD) precursor. High oxidative stress will affect in low antioxidant activity levels[8].

Antioxidants couldinfluence themetabolism of cholesterol. Antioxidants can prevent fatty acid oxidation process so that atherosclerosis is not formed. Endogenous antioxidants such as glutathione peroxidase, catalase, and superoxide dismutase under certain conditions are depleted so that the body requires exogenous antioxidants[9]. Antioxidant likes Vitamin E, Vitamin C, beta-carotene, coenzyme q10, quercetin and other bioflavonoids are few examples of exogenous antioxidants. The use of antioxidants, especially coenzyme Q10 to treatdiabetic hypercholesterolemia-induced periodontitishas not been elucidated.Some fish contain more coenzymes Q10 than vegetables.

Coenzyme Q10 has been known to have a high antioxidant capacity and clinical effect[10][11][12]. Besides, coenzyme Q10 is an active redox lipid that serves as a cofactor in the electron transfer chain in the mitochondria and plasma membranes[13]. Coenzyme Q10 $300 \mathrm{mg} /$ day is effective antioxidant and anti-inflammatory agent that can reduce TNF$\alpha$ and IL-6 levels in CHD patients [14]. Previous research has shown that coenzyme Q10 and vitamin $\mathrm{E}$ are interrelated, but other studies have shown that is not correlated[15]. This study aimed to analyze the effect of coenzyme Q10 on the lipid profile ofdiabetic hypercholesterolemia-induced periodontitis rats.

\section{Method}

\subsection{Research subject}

Thisis an experimental research with pretest-posttest with control group design. Rattusnovergicuswas a male rat, Sprague Dawley strain, age 2-3 months, body weight 150200 grams.Twenty four rats were randomly grouped into 6 groups. A healthy control group (G1) of the rat only fed corn oil. Group 2 (G2) serving as the negative control group washypercholesterolemia and diabetic-induced periodontitis rats, then given corn oil. Group 3 (G3) as the positive control was hypercholesterolemia and diabetic-induced periodontitis rats and then given Vitamin $\mathrm{E}$ at the dose of $27 \mathrm{mg} / \mathrm{kg}$. The treatment groups (G4-G6) were hypercholesterolemiaand diabetic-induced periodontitis rat, then given coenzyme Q10 at the dose of 13,$5 ; 27$; and $54 \mathrm{mg} / \mathrm{kg}$ respectively.Lipid profile examination was conducted before and after the treatment.

\subsection{Laboratory experiments}

Rats were adapted for one week and placed in separate cages according to the group. Rats were housed in polyethylene cages ( 5 rats/cage) with stainless steel wire tops and were allowed for commercial standard diet and water ad-libitum. Rats were housed under standard laboratory conditions. Standard care methods were used to keep the animals healthy and free of infections. The principles of the animal care trial have followed the code of conduct of animal research trial. The research was carried out after obtaining an ethical clearance from the Ethics Commission of Faculty of Medicine UNS, Surakarta. 
Periodontitis was induced by inoculation of A. actinomycetescomitans bacterial species at a dose of 1 Mcfarland (equivalent to 108 density) of $200 \mu \mathrm{L}$ or $0.2 \mathrm{~mL}$ daily for 7 days in the mandibular incisor.Hypercholesterolemia was induced with a high-fat diet (yellow duck egg $4 \mathrm{~mL} / 200 \mathrm{~g}$ ) for 7 days. Rats were induced to be diabeticby streptozotocin (STZ) injection with a single dose of $60 \mathrm{mg} / \mathrm{kg}$. Coenzyme Q10 in the form of a $100 \mathrm{mg}$ blue tablet preparation produced by Nutrimaxwas diluted with corn oil. The coenzyme Q10 at a dose of 13.5; 27 and $54 \mathrm{mg} / \mathrm{kg}$ was administered orally using $2 \mathrm{~mL}$ gastric tube once a day for 14 days. Lipid profile including triglycerides and HDL were measured enzymatically by using the CHOD-PAP method, while atherogenic index (IA) was calculated using log 10 (TG/HDLc).

\subsection{Statistical analysis}

The data were expressed as the mean \pm standard deviation (SD) and presented in frequency distribution table. The mean difference between groups was examined using one-way analysis of variance (ANOVA) followed by the post Hoc Least Significant Difference (LSD) test for multiple comparisons. The test is considered significant if $\mathrm{p}<0.05$.

\section{Results}

On the 8th day after induction of periodontitis, one of each group was anesthetized with chloroform and decapitated, then radiographic examination was done in a periapical photograph to ensure bone resorption. The induction of streptozotocin and HFD significantly increased blood glucoseand cholesterol levels compared with healthy controls $(p<0.05)$. Mean triglyceride and atherogenic levels decreased and HDL increased significantly after the treatment period $(\mathrm{p}<0.05)$. The results of ANOVA test on triglyceride, HDL and atherogenic index before treatment showed significant differences between group G1 and G2-G6 group $(p<0.05)$ but did not differ significantly between groups G2-G6 ( $p>0.05)$. This suggests that cholesterol induction and diabetes mellitus were successfully performed in the G2-G6 group (Figure 1).

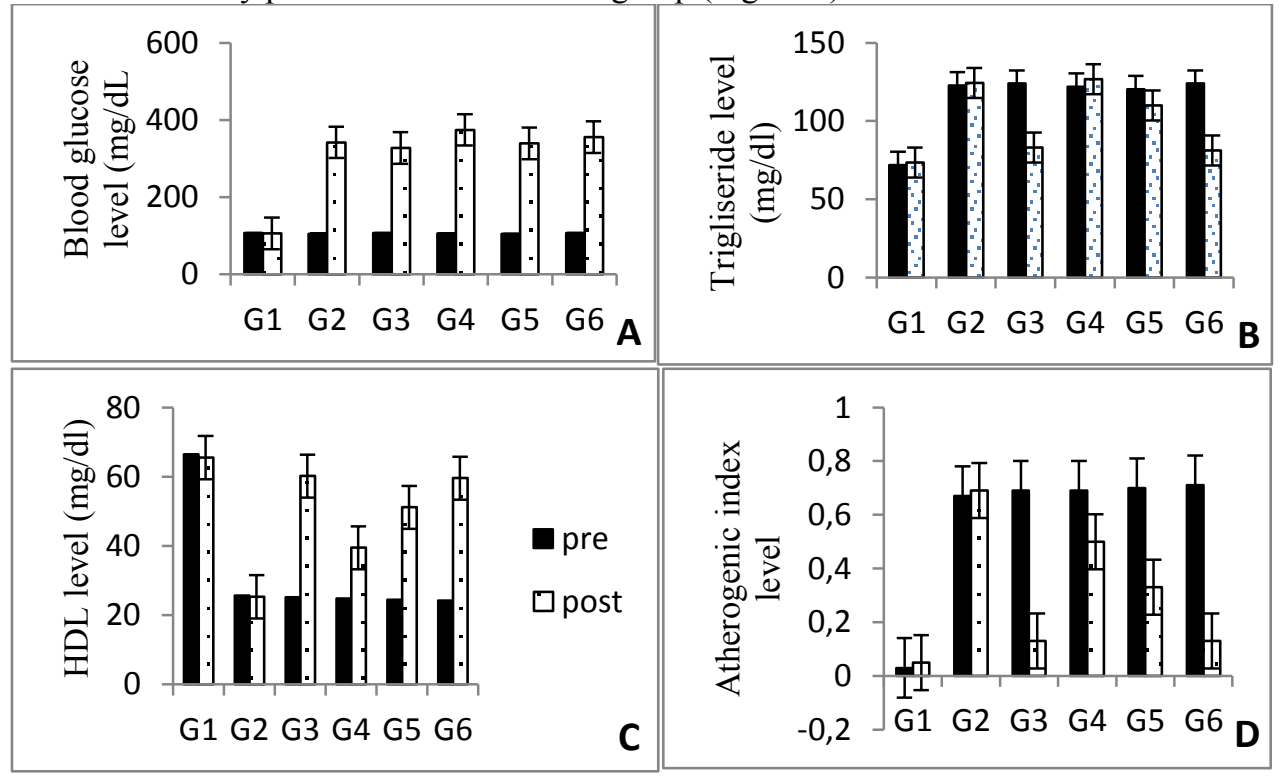

Fig. 1.Blood glucose, HDL, Triglyceride levels andAtherogenic index before and after treatment.

*Corresponding author: sarbiokim@gmail.com 
Levels of triglycerides before treatment showed no significant differences between treatment groups G2-G6, but significantly different from healthy control group (G1). After the treatment period, ANOVA test results showed significant differences in triglyceride levels between groups $(p<0.05)$. The G3 and G6 treatment groups had the lowest triglyceride levels (ie $82.94 \mathrm{mg} / \mathrm{dl}$ and $81.15 \mathrm{mg} / \mathrm{dl}$ ) and no significant difference between G3 and G6. This suggests that the administration of coenzyme q10 dose of $54 \mathrm{mg} / \mathrm{kg}$ is equal to vitamin $\mathrm{E}$ dose of $27 \mathrm{mg} / \mathrm{kg}$. The post hoc LSD test showed differences in all groups ( $<<0.05$ ), except G3, G4, and G6 (Table 1). The groups of G2 with G4 and G3 with G6 are not significantly different.

Table 1. The result of LSD test on triglyceride level after treatment

\begin{tabular}{|l|c|c|c|c|c|c|}
\hline Groups & G1 & G2 & G3 & G4 & G5 & G6 \\
\hline G1 & - & $0.000^{*}$ & $0.000^{*}$ & $0.000^{*}$ & $0.000^{*}$ & $0.003^{*}$ \\
\hline G2 & $0.000^{*}$ & - & $0.000^{*}$ & 0.265 & $0.000^{*}$ & $0.000^{*}$ \\
\hline G3 & $0.000^{*}$ & $0.000^{*}$ & - & $0.000^{*}$ & $0.000^{*}$ & 0.436 \\
\hline G4 & $0.000^{*}$ & 0.265 & $0.000^{*}$ & - & $0.000^{*}$ & $0.000^{*}$ \\
\hline G5 & $0.000^{*}$ & $0.000^{*}$ & $0.000^{*}$ & $0.000^{*}$ & - & $0.000^{*}$ \\
\hline G6 & $0.003^{*}$ & $0.000^{*}$ & 0.436 & $0.000^{*}$ & $0.000^{*}$ & - \\
\hline \multicolumn{7}{|c}{} \\
\hline
\end{tabular}

HDL levels before treatment showed no significant differences between groups G2-G6, but significantly different from healthy control group (G1). After the treatment period, there was a significant difference of HDL levels between groups $(p<0.05)$. The mean HDL levels were highest in the G1 group $(65.52 \mathrm{mg} / \mathrm{dl})$, but in the treatment group, the highest HDL levels were found G3 $(60.15 \mathrm{mg} / \mathrm{dl})$ and G6 $(59.57 \mathrm{mg} / \mathrm{dl})$. There was no significant difference in HDL levels between the positive control group (G3) and G6 group given coenzyme Q10 dose $54 \mathrm{mg} / \mathrm{kg}$. Based on the LSD post hoc test, all groups differed significantly $(\mathrm{p}<0.05)$, except G3 with G6 (Table 2).

Table 2. The result of LSD test on HDL level after treatment

\begin{tabular}{|l|c|c|c|c|c|c|}
\hline Groups & G1 & G2 & G3 & G4 & G5 & G6 \\
\hline G1 & - & $0.000^{*}$ & $0.000^{*}$ & $0.000^{*}$ & $0.000^{*}$ & $0.000^{*}$ \\
\hline G2 & $0.000^{*}$ & - & $0.000^{*}$ & $0.000^{*}$ & $0.000^{*}$ & $0.000^{*}$ \\
\hline G3 & $0.000^{*}$ & $0.000^{*}$ & - & $0.000^{*}$ & $0.000^{*}$ & 0.634 \\
\hline G4 & $0.000^{*}$ & $0.000^{*}$ & $0.000^{*}$ & - & $0.000^{*}$ & $0.000^{*}$ \\
\hline G5 & $0.000^{*}$ & $0.000^{*}$ & $0.000^{*}$ & $0.000^{*}$ & - & $0.000^{*}$ \\
\hline G6 & $0.000^{*}$ & $0.000^{*}$ & 0.634 & $0.000^{*}$ & $0.000^{*}$ & - \\
\hline \multicolumn{7}{|c}{} \\
\hline
\end{tabular}

Atherogenic index before treatment showed no significant difference between treatment groups (G2-G6), but significantly different from healthy control group (G1). After the treatment period, the mean atherogenic index was decreased. The lowest rates of the atherogenic index were found in the G3 (0.138) and G6 (0.135) groups, but there was no significant difference between the groups. This shows that coenzyme Q10 dose of $54 \mathrm{mg} / \mathrm{kg}$ is as effective as vitamin $\mathrm{E}$ dose of $27 \mathrm{mg} / \mathrm{kg}$. From the post hoc test, it was found that all groups had significant differences in the atherogenic index, except for the G3 and G6 groups (Table 3). 
Table 3. The result of LSD test on atherogenic index after treatment

\begin{tabular}{|c|c|c|c|c|c|c|}
\hline Groups & G1 & G2 & G3 & G4 & G5 & G6 \\
\hline G1 & - & $0.000^{*}$ & $0.000 *$ & $0.000^{*}$ & $0.000^{*}$ & $0.000^{*}$ \\
\hline G2 & $0.000^{*}$ & - & $0.000^{*}$ & $0.000^{*}$ & $0.000^{*}$ & $0.000^{*}$ \\
\hline G3 & $0.000 *$ & $0.000^{*}$ & - & $0.000^{*}$ & $0.000^{*}$ & 0.862 \\
\hline G4 & $0.000 *$ & $0.000^{*}$ & $0.000 *$ & - & $0.000^{*}$ & $0.000 *$ \\
\hline G5 & $0.000^{*}$ & $0.000^{*}$ & $0.000 *$ & $0.000^{*}$ & - & $0.000^{*}$ \\
\hline G6 & $0.000^{*}$ & $0.000^{*}$ & 0.862 & $0.000 *$ & $0.000 *$ & - \\
\hline
\end{tabular}

\section{Discussion}

Coastal areas are generally synonymous with poor healthy lifestyle patterns, low levels of education and awareness of poor health. The unavailability of qualified drinking water sources has the potential to increase the incidence of periodontitis[3]. Characteristics of infertile soil also cause at least fruit plants so that the consumption of food sources of antioxidants is lower. This is the first study to overcome the problem of periodontitis in coastal areas.

After induction of bacteria in the tooth, rats undergo periodontitis, then STZ-induced to occur diabetes. The mean of blood sugar level before induction was $106,21 \mathrm{mg} / \mathrm{dl}$, but after induction, it increased to $347,75 \mathrm{mg} / \mathrm{dl}$. This suggests that all of the G2-G6 groups had reached the condition of diabetes. The success of hypercholesterolemia and diabetes induction can be seen from the difference of all healthy control group (G1) indicator with the negative control group (G2) significantly $(\mathrm{p}<0.05)$. STZ injection works by destroying pancreatic $\beta$ cells, resulting in DNA changes. STZ inhibits the Krebs cycle and decreases oxygen consumption in the mitochondria, resulting in cell death. STZ also induces the formation of radical oxygen species (ROS) causing oxidative stress. This further results in decreasingof insulin synthesis and leads to diabetes.

Coenzyme Q10 is an important cofactor for the electron transport chain within the mitochondria and also acts as an antioxidant. Coenzyme Q10 works through the mechanism of repair of mitochondrial function in pancreatic cells thus increasing the production of insulin again. In addition, the coenzyme Q10 also works to inhibit lipid and protein peroxidase. Coenzyme Q10 plays a primary role in preventing the formation of lipid peroxidase (LOO) radicals[16], thereby reduce total cholesterol and LDL. Coenzyme Q10 works through microRNA (miRNA) that increases cholesterol efflux and inhibit atherosclerosis[17] so the HDL level increases.

The inflammatory response caused by STZ exposure and a high-fat diet in mice can also be reduced by coenzyme Q10. Free radicals caused by STZ oxidizes the pancreatic beta cells resulting in inflammation. Co-administration of Q10 may work as an antiinflammatory [10], as evidenced by decreased in TNF- $\alpha$, CRP and IL-6 in male runners[18]. High LDL after STZ injection can be resulted from an inflammatory reaction due to LDL oxidation. In lipid profile, the antioxidant ability of coenzyme Q10 (at G6) has an equal potency as vitamin E. In another study, coenzyme Q10 was significantly positively correlated with another antioxidant capacity (vitamin E and glutathione peroxidase activity)[19]. Vitamin $\mathrm{E}$ is a fat-soluble vitamin that is very effective in protecting cell membranes from free radical oxidation. Vitamin $\mathrm{E}$ antioxidants including secondary antioxidants work by capturing and preventing chain reactions, especially on lipid peroxidation by capturing peroxyl radicals.

Administration of coenzyme Q10 with 3 dose variations showed the greatest effect at the highest dose of $54 \mathrm{mg} / \mathrm{kg}$ (group G6). This suggests that the most effective dose in

*Corresponding author: sarbiokim@gmail.com 
improving the lipid profile is a dose of $54 \mathrm{mg} / \mathrm{kg}$. However, the dose of coenzyme Q10 was comparable to that of the positive control group given vitamin E dose $27 \mathrm{mg} / \mathrm{kg}$. Vitamin E and coenzyme q10 work to inhibit lipid peroxidation. Coenzyme Q10 and tocopherol are lipid phase micronutrients that prevent oxidative damage and distributed commonly in peripheral blood plasma[20]. Low levels of coenzyme Q10 in the body will increase mortality due to organ dysfunction[21], and administration of coenzyme Q10 may reduce symptoms of organ dysfunction such as heart failure[22].

Coenzyme Q10 oxidized with reduced ratio was positively correlated with malondialdehyde (MDA) and glutathione peroxidase activity (GPX) ratio[23]. This suggests that the role of coenzyme Q10 as an antioxidant to protect lipids from the free radical oxidation is very important. Coenzyme Q10 can also increase the capacity of antioxidant and cellular energy metabolism in the skin[24]. At a dose of $300 \mathrm{mg} / \mathrm{d}$, coenzyme Q10 supplementation significantly increased antioxidant capacity and reduced oxidative stress and inflammatory response in patients with hepatocellular carcinoma after surgery[25].

Coenzyme Q10 works primarily as an electron carrier during cellular respiration and as an intracellular antioxidant. Reduced coenzyme Q10 is a free radical scavenger that protects LDL against oxidative stress. The reduced coenzyme Q10 works to reduce the lipid peroxyl and tocopheryl radicals and minimize oxidative stress through the dehydrogenation reaction in the oxidized coenzyme Q10. Thus, coenzyme Q10 works to strengthen the performance of vitamin E. The combination of coenzyme Q10 with atorvastatin in hypercholesterolemic rats can improve the biochemical parameters and respiratory function of mitochondrial hepatic rats[14][26][27].

These findings have clinical implications to applied in coastal areas. Coenzyme Q10 can be given to coastal communities to reduce the occurrence of periodontitis. There are many food sources of coenzyme q10 available in addition to vegetables and fruits in coastal areas. Sardines, mackerel, salmon, and tuna fish contains a lot of coenzyme Q10. But still, need further research with larger samples and effective dose in humans.

There are several limitations in this study. The response of adaptation and immunity of rats varies and inflammatory indicators were not measured. Glucose levels after treatment were not measured so it could not explain the effect of coenzyme Q10 on rat blood glucose.

\section{Conclusion}

The $54 \mathrm{mg} / \mathrm{kg}$ dose of coenzyme Q10 is effective in lowering triglyceride and atherogenic index and raising HDL levels in blood model of diabetic hyperlipidemia-induced periodontitis. Antioxidant ability of coenzyme Q10 dose of $54 \mathrm{mg} / \mathrm{kg}$ is equal to vitamin E dose $27 \mathrm{mg} / \mathrm{kg}$. Coenzyme Q10 can replace the requirement of vitamin E in the body to increase the body's antioxidant capacity in the coastal area.

\section{Acknowledgment}

The researcher would like to extend our deepest gratitude to Dr. Hernayanti for her laboratory assistance.

\section{References}

1. S. Kumar, S. Lata, J. Yadav, J.P. Yadav, Appl.. Water. Sci. 7, 3, 377-84(2017)

2. P. Bhattacharya, A.C. Samal,S. Banerjee,J. Pyne, S.C. Santra, India Environ. Sci. Pollut. Res. 24, 20300-14 (2017)

3. P. Pandey, A. Sharma, Int. J. Adv. Res. Sci. Eng. 7 503-9 (2018)

4. Agency for Health Research and Development, Ministry of Health Republic of Indonesia,Basic Health Research (Riskesdas) (2013) 
5. A. Fitriyanti,A.Susilowati, U.N.A. Darjono, Odonto Dent. J. 1 6-10 (2014)

6. R. Sari,D. Herawati, R. Nurcahyanti, P.K. Wardani, Maj. Kedokt. Gigi Indones. 398 104 (2017)

7. S. Saryono, J. Eliyan,D. Herdiati,A. Khikmatullah, C. Silvana, H. Adi, IOP Conf. Ser. Mater. Sci. Eng. 172 (2017)

8. B. Lee, Y. Huang, S. Chen, P. Lin, Nutrition 28 250-5 (2012)

9. C. Yen,N. Yang, B. Lee,J. Lin,S. Hsia, P. Lin, Sci. J. 2013 1-7 (2013)

10. R. Pala,C. Orhan,M. Tuzcu,N. Sahin,S. Ali, V. Cinar,K. Sahin, J. Sport. Sci. Med. 15 196-203 (2016)

11. L. Peverelli,A. Naini,M. Hirano, M. Catarina, Ann. Clin. Pathol.2 1-4 (2014)

12. A. Sharma,G.C. Fonarow,J. Butler, J.A. Ezekowitz, G.M. Felker, Circ. Hear. Fail. 9 19 (2016)

13. M. Potgieter,E. Pretorius,C.F. Van der Merwe, M. Beukes, W.A. Viera, R.E.G. Auer, M. Auer, S. Meyer, Micron. 42 275-82 (2011)

14. B. Lee, Y. Tseng, C. Yen, P. Lin, Nutr. J. 12 1-9 (2013)

15. N. Naidoo, R. M. van Dam, W. Koh, C. Chen, Y. Lee, J. Yuan, C. Ong, Chinese J. Nutr.142 1046-52 (2012)

16. T. Grenier-larouche, A. Galinier, L. Casteilla, A.C. Carpentier, A. Tchernof, J. Lipid Res. 56 1985-92 (2015)

17. R.M. Allen, K.C. Vickers, Thromb. Vasc. Biol. 34 1795-7 (2015)

18. M. Armanfar, A. Jafari, G.R. Dehghan, L. Abdizadeh, Med. J. Islam. Repub. Iran 29(2015)

19. H. Liu,Y. Huang, S. Cheng,Y. Huang,P. Lin, Nutr. J. 15 1-9 (2016)

20. A. Franke,J.F. Lai, C.M. Morrison, I. Pagano,X. Li, B.M. Halm, R. Soon, L.J. Custer, Free. Radic. Res.47 757-68 (2015)

21. A. Coppadoro,L. Berra,A. Kumar, R. Pinciroli,M. Yamada, U.H. Schmidt, E.A. Bittner, M. Kaneki, J. Crit. Care.28 571-6 (2013)

22. A. D. Fotino, A.M. Thompson-Paul, L.A. Bazzano, Am. J. Clin. Nutr.97 268-75 (2013)

23. Y. Kaya,A. Çebİ, N. Söylemez, H. Demİr, H.H. Alp, E. Bakan, Int. J. Med. Sci. 9 (2012)

24. A. Knott,C. Smuda,G. Sperling,A. Vogelsang, H. Schwengler, S. Kristof, T. Eisenberg, T. Blatt, BioFactors, 41 383-90 (2015)

25. H. Liu, S. Cheng,Y. Huang, Y. Huang, Nutrients, 9 1-9 (2017)

26. M.A. Jiménez-santos, I.E. Juárez-rojop, C.A. Tovilla-zárate, M.T. Espinosa-garcía, M.A. Juárez-oropeza,T. Ramón-frías, D.Y. Bermúdez-ocaña,J.C. Díaz-zagoya, Lipids Health Dis. 13 1-10 (2014)

27. A. Skarlovnik, M. Janić, M. Lunder, M. Turk, M. Šabovič,Med. Sci. Monit.20 2183-8 (2014) 